\title{
LPA and PLG Sequence Variation and Kringle IV-2 Copy Number in Two Populations
}

\author{
Dana C. Crawford ${ }^{a} \quad Z^{2}$ Peng $^{b} \quad$ Jan-Fang Cheng ${ }^{b}$ Dario Boffelli ${ }^{b}$ \\ Magdalena Ahearn ${ }^{c}$ Dan Nguyen ${ }^{c}$ Tristan Shaffer ${ }^{c}$ Qian Yic \\ Robert J. Livingston ${ }^{c}$ Mark J. Rieder ${ }^{c}$ Deborah A. Nickerson ${ }^{c}$ \\ aDepartment of Molecular Physiology and Biophysics, Center for Human Genetics Research, Vanderbilt University, \\ Nashville, Tenn.; ${ }^{b}$ Genomics Division and Joint Genome Institute, Lawrence Berkeley National Laboratory, \\ Berkeley, Calif.; and 'Department of Genome Sciences, University of Washington, Seattle, Wash., USA
}

\section{Key Words}

African-American $\cdot$ Apo(a) $\cdot$ Kringle $\cdot \mathrm{Lp}(\mathrm{a}) \cdot$ Plasminogen $\cdot$

Sequencing $\cdot$ Linkage disequilibrium

\begin{abstract}
Background/Aims: Lp(a) levels have long been recognized as a potential risk factor for coronary heart disease that is almost completely under genetic control. Much of the genetics impacting $L p(a)$ levels has been attributed to the highly polymorphic LPA kringle IV-2 copy number variant, and most of the variance in $L p(a)$ levels in populations of Europeandescent is inversely correlated with kringle IV copy number. However, less of the variance is explained in African-descent populations for the same structural variation. African-descent populations have, on average, higher levels of $\operatorname{Lp}(\mathrm{a})$, suggesting other genetic factors contribute to $L p(a)$ level variability across populations. Methods: To identify potential cis-acting factors, we re-sequenced the gene $L P A$ for single nucleotide polymorphism (SNP) discovery in 23 European-Americans and 24 African-Americans. We also resequenced the neighboring gene plasminogen (PLG) and genotyped the kringle IV copy number variant in the same reference samples. Results: These data are the most comprehensive description of sequence variation in LPA and its
\end{abstract}

relationship with the kringle IV copy number variant. With these data, we demonstrate that only a fraction of LPA sequence diversity has been previously documented. Also, we identify several high frequency SNPs present in the AfricanAmerican sample but absent in the European-American sample. Finally, we show that SNPs within PLG are not in linkage disequilibrium with SNPs in $\angle P A$, and we show that kringle IV copy number variation is not in linkage disequilibrium with either LPA or PLG SNPs. Conclusions: Together, these data suggest that LPA SNPs could independently contribute to $L p(a)$ levels in the general population.

Copyright $\odot 2008$ S. Karger AG, Basel

\section{Introduction}

Lipoprotein (a) $[\mathrm{Lp}(\mathrm{a})]$ particles, similar to low density lipoprotein (LDL) particles, contain a lipid core surrounded by unesterified cholesterol, phospholipids, and apolipoprotein B-100 [reviewed in 1]. The factor distinguishing Lp(a) from LDL is the addition of the glycoprotein apolipoprotein(a), also known as LPA encoded by the gene $L P A$, linked to apolipoprotein B-100 via a disulfide bond [2]. LPA is expressed in the liver [3], and there is evidence that the assembly of apo(a) and apo B-100 to

\section{KARGER}

Fax +41613061234 E-Mail karger@karger.ch www.karger.com
(C) 2008 S. Karger AG, Basel

0001-5652/08/0664-0199\$24.50/0

Accessible online at:

www.karger.com/hhe
Dana C. Crawford, PhD

Department of Molecular Physiology and Biophysics

Center for Human Genetics Research, Vanderbilt University

515B Light Hall, 2215 Garland Avenue, Nashville, TN 37232 (USA)

Tel. +1 615343 7852, Fax +1 615343 8619, E-Mail crawford@chgr.mc.vanderbilt.edu 
produce the final $\mathrm{Lp}(\mathrm{a})$ particle occurs on the surface of the hepatocytes [4]. Lp(a) levels are thought to be relatively constant throughout a person's lifetime; however, there are reports that $L p(a)$ levels are correlated with age [5], and intra-individual levels can vary significantly with repeated measurements $[6,7]$.

A remarkable feature of $\operatorname{Lp}(\mathrm{a})$ levels is its inter-individual variability, ranging from barely detectable to $>250$ $\mathrm{nmol} / \mathrm{l}$ [8]. LPA is the major determinant of this plasma $\mathrm{Lp}$ (a) variability. LPA is structurally homologous to plasminogen [9], and both of their respective genes (LPA and $P L G$ ) lie on chromosome 6q26 within approximately 40 kilobases of one another, strongly suggesting that $L P A$ arose from a duplication event. Furthermore, LPA is found only in Old World primates and hedgehog, and genomic evidence suggests this has occurred through convergent evolution [10]

LPA, compared with plasminogen, contains an inactive protease domain and a highly variable number of copies of the kringle IV-2 domain. It is the kringle IV-2 repeat (two exons flanking one intron totaling $5.5 \mathrm{~kb}$ per repeat unit) in the $L P A$ gene that gives rise to the polymorphic DNA structure and extreme variability in $\mathrm{Lp}(\mathrm{a})$ plasma levels. Estimates suggest that the number of kringle IV-2 repeats alone contained within the Lp(a) complex explains $61-69 \%$ of the variability observed in $L p(a)$ levels for European-descent populations [11, 12]. Studies in non-European-descent populations estimate that the kringle IV-2 repeat explains less of the variance in $\mathrm{Lp}(\mathrm{a})$ levels (19-44\%) compared with European-descent populations [13-17].

High Lp(a) levels are an independent risk factor for coronary heart disease [18] and future cardiovascular events [19], but not for coronary artery calcification [20]. Of the few studies that included African-descent populations, high Lp(a) levels are inconsistently associated with coronary artery disease risk $[21,22]$, yet African-descent populations have on average 2-3 times higher levels of Lp(a) compared with European-descent populations [16, 23]. The difference in $\mathrm{Lp}(\mathrm{a})$ levels between populations has yet to be explained. For European-descent populations, $\mathrm{Lp}(\mathrm{a})$ levels are inversely correlated with LPA kringle IV-2 repeat copy number $[16,24]$. This inverse correlation is less striking in African-descent populations [13, $16,17]$.

Genetic factors may play a role in the difference observed for Lp(a) levels in European- and African-descent populations. For all populations studied to date, $\mathrm{Lp}(\mathrm{a})$ levels are highly heritable $[11,14,25,26]$, and most $[11,14$, 26] but not all studies [25] suggest that the LPA locus itself is the major determinant of $\mathrm{Lp}$ (a) levels. While the kringle IV-2 repeat polymorphism accounts for over half of the variance in $L p(a)$ levels, the remaining variance remains unexplained. Current evidence suggests that genetic variations (other than the kringle IV-2 repeat polymorphism) within or closely linked to $L P A$ are responsible for $L p(a)$ level variation rather than trans-acting factors [27]. Thus, it may be these yet-undescribed cisacting factors play a substantial role in shaping the $\mathrm{Lp}(\mathrm{a})$ trait distribution among human populations.

To begin the process of identifying these cis-acting genetic factors, we genotyped the kringle IV-2 repeat and re-sequenced the $L P A$ and PLG genes in 23 European- and 24 African-American samples of presumably healthy men and women for single nucleotide polymorphism (SNP) discovery. With these data, we are able to describe here for the first time the natural variation contained within $L P A$ as well as linkage disequilibrium across this locus containing the polymorphic kringle IV-2 repeat and across the flanking gene PLG. Collectively, these data and observations lay the foundation for the design and interpretation of the next generation $\mathrm{Lp}(\mathrm{a})$ genetic association studies.

\section{Materials and Methods}

\section{Sequencing}

LPA and PLG were re-sequenced by SeattleSNPs, a member of NHLBI's Program for Genomic Applications. A total of 47 samples from Coriell Cell Repositories were re-sequenced: 23 European-Americans (NA12560, NA12547, NA10845, NA10853, NA10860, NA10830, NA10842, NA10851, NA07349, NA10857, NA10858, NA10848, NA12548, NA10844, NA10854, NA10861, NA10831, NA10843, NA10850, NA07348, NA10852, NA06990, NA07019) and 24 African-Americans (members of the AfricanAmerican panel of 50: NA17101-NA17116; NA17133-NA17140). The unrelated European-American samples represent 23 DNA samples from the original Centre d'Etude du Polymorphisme Humain (CEPH) reference panel, which consists of 61 large, presumably healthy families from the United States or France ascertained for the purpose of gene mapping [28]. Recent studies have suggested that genetic variation observed in both the CEPH and African-American panel DNA samples is representative of other U.S. populations of European- or African-descent [29-33].

Sequencing was performed on an ABI3730 using standard Big Dye terminator chemistry. We targeted the genomic sequence of $L P A$ for re-sequencing, but excluded the variable kringle regions and other regions because these genomic sequences mapped to several regions of $L P A$ of similar sequence (as was the case for the kringle region) or did not uniquely map to $L P A$. From a target of $136,345 \mathrm{bp}$, we were able to re-sequence $56,071 \mathrm{bp}(41 \%)$ for variation discovery. For PLG, approximately $24.5 \mathrm{~kb}$ of sequence was targeted from a total of $55.3 \mathrm{~kb}$ of sequence containing the gene. We also targeted the $\sim 40 \mathrm{~kb}$ of sequence between $L P A$ and PLG for variation discovery. All DNA variation and genotype data for 


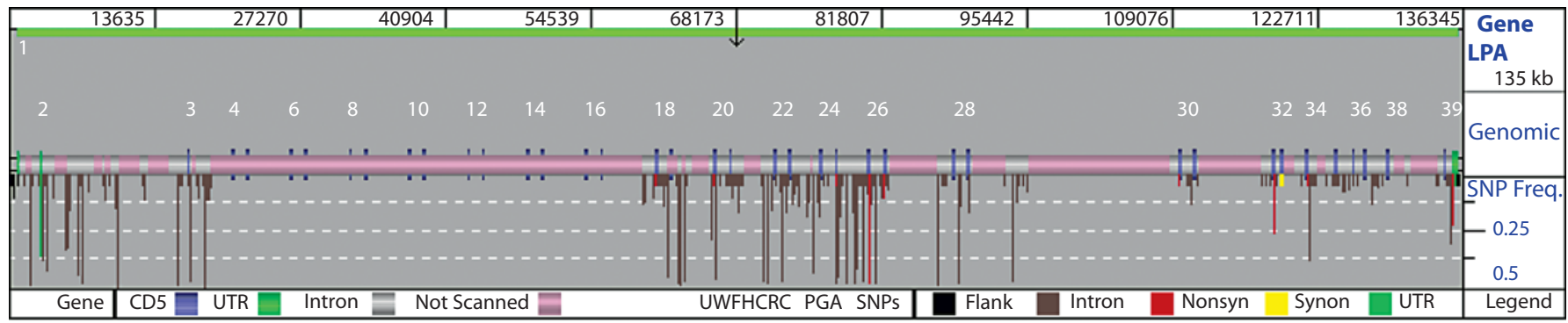

a

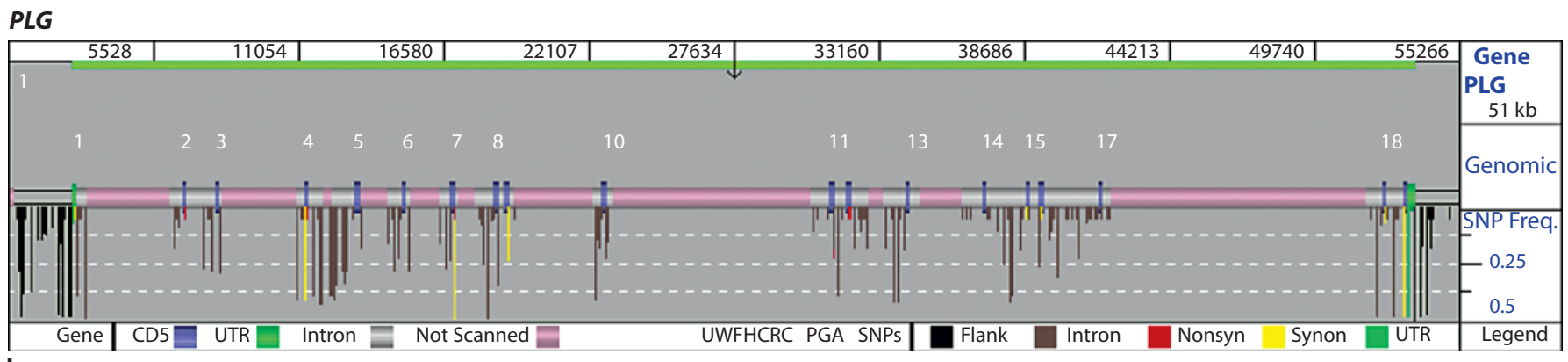

Fig. 1. A view of sequence coverage of $L P A$ (a) and $P L G$ (b) for genetic variation discovery in 47 DNA samples. Genome sequence targeted for re-sequencing is color-coded so that grey represents introns, blue represents coding sequence, and green represents untranslated regions. Targeted sequence not scanned for variation discovery is represented in pink. SNPs are marked by bars color-coded to represent the location and type of SNP (black for flanking, brown for intronic, red for nonsynymous, yellow for synonymous, and green for untranslated region), and the length of the bar represents the frequency of each SNP in the total population of 47 samples.

$L P A$ and $P L G$ were deposited in GenBank (accession numbers DQ452068 and AY192161, respectively), dbSNP, and the SeattleSNPs website (http://pga.gs.washington.edu). Location, rs numbers (where available), and sequence context of the DNA variations annotated in this discovery effort for $L P A$ and $P L G$ are also given in Supplementary tables 1 and 2 (www.karger.com/doi/ $10.1159 / 000143403)$, respectively. Figure 1 describes the sequence coverage for both $L P A$ (a) and PLG (b) compared with the genomic sequence targeted for variation discovery.

Preparation of Genomic DNA for Kringle Genotyping

We genotyped the kringle repeat in the 47 individuals that were re-sequenced for $L P A$ and PLG variation discovery. GM cells were obtained from the Coriell Cell Repository and have the same identification number as the DNA samples listed for re-sequencing with the exception that the initials ' $G M$ ' denote cell lines while initials 'NA' denote DNA samples.

GM cells were propagated in RPMI-1640 with 10\% FCS, harvested and washed with $\mathrm{Mg}^{2+}$-free PBS, and mixed with an equal volume of pre-warmed $1 \%$ InCert agarose (FMC) at the final cell concentration of $10^{7} / \mathrm{ml}$. The agarose was added to pre-cooled disposable plug molds (BioRad, Hercules, CA) at $100 \mu \mathrm{l} / \mathrm{mold}$. After gel plugs forming, 1-6 plugs were treated with $1 \mathrm{ml}$ ESP $(0.5 \mathrm{M}$ EDTA pH 9.5, 2\% SLS, $2 \mathrm{mg} / \mathrm{ml}$ Proteinase K) for $48 \mathrm{~h}$ at $50^{\circ} \mathrm{C}$ and with fresh ESP for another $24 \mathrm{~h}$. Plugs were stored in fresh ESP at $4^{\circ} \mathrm{C}$.

Sequence Variation in $L P A$ and $P L G$

\section{Southern Blot Hybridization for Kringle Genotyping}

DNA plugs were washed with TE buffer $(1.8 \mathrm{ml} / \mathrm{plug})$ and $1 \mathrm{mM}$ PMSF for $30 \mathrm{~min}$ twice, followed by TE ( $5 \mathrm{ml} / \mathrm{plug}$ ) wash for $30 \mathrm{~min}$ twice and TE $(1 \mathrm{ml} / \mathrm{plug})$ wash once for $30 \mathrm{~min}$. After the TE washes, only $1 / 2$ of a plug from each cell line was used in restriction enzyme digest. DNA plugs were first washed in $150 \mu \mathrm{l}$ of restriction enzyme reaction buffer $(1 \times$ NEBuffer 1 , New England Biolabs) for $30 \mathrm{~min}$. All washes were carried out at $4^{\circ} \mathrm{C}$ with slow shaking. DNA plugs were then incubated with $100 \mu \mathrm{l} \mathrm{Kpn} \mathrm{I} \mathrm{digest}$ solution $(1 \times$ NEBuffer $1,1 \mathrm{mg} / \mathrm{ml} \mathrm{BSA}, 40 \mathrm{U} \mathrm{Kpn} \mathrm{I})$ at $37^{\circ} \mathrm{C}$ for $2 \mathrm{~h}$. After digest, DNA plugs were run with size standards (NEB lambda DNA and MidRange I) on 1\% agarose gel in the TAE buffer (40 mM Tris-acetate, and $1 \mathrm{~mm}$ EDTA, $\mathrm{pH}$ 8.0) by pulsed-field gel electrophoresis (PFGE) and the running condition of $6 \mathrm{~V} / \mathrm{cm}$, $120^{\circ} \mathrm{C}, 2.9-17.3 \mathrm{~s}$ ramping pulse time for $27 \mathrm{~h}$ at $14^{\circ} \mathrm{C}$. After PFGE, the gels were stained with $0.5 \mu \mathrm{g} / \mathrm{ml}$ of $\mathrm{EtBr}$ for $30 \mathrm{~min}$, treated with UV light on the UV transilluminator 2000 (BioRad) for $90 \mathrm{~s}$, followed by denaturing buffer $(3 \mathrm{M} \mathrm{NaCl}$ and $0.5 \mathrm{~N} \mathrm{NaOH})$ for $30 \mathrm{~min}$, neutralizing buffer $(0.5 \mathrm{M}$ Tris- $\mathrm{HCl} \mathrm{pH} \mathrm{7.5,} 1.5 \mathrm{M} \mathrm{NaCl})$ for $30 \mathrm{~min}$ and $10 \times \mathrm{SSC}(1.5 \mathrm{M} \mathrm{NaCl}$ and $0.15 \mathrm{M}$ sodium citrate) for 30 min with shaking. Fractionated DNA was then blotted to the Hybond-N membrane (GE Healthcare, RPN1520N) for $4 \mathrm{~h}$ and immobilized by baking at $65^{\circ} \mathrm{C}$ for $2 \mathrm{~h}$ and cross-linking with the UV Stratalinker 2400 (Stratagene) for $30 \mathrm{~s}$. The probe was generated by PCR (primers: 5'-TCCAGCAATTGGCAAATGTA-3' and $5^{\prime}$-CTGCCCTGAAAAACTTGCTC-3') that amplifies an 
Table 1. Sequence variation

\begin{tabular}{lcll}
\hline Population & S & $\begin{array}{l}\text { Common } \\
\text { SNPs } \\
(\text { MAF }>10 \%)\end{array}$ & $\begin{array}{l}\pi \\
\text { (Tajima's D) }\end{array}$ \\
\hline a $\quad$ PPA & & & \\
African-American $(\mathrm{n}=24)$ & 232 & 78 & $40.74(-0.8505)$ \\
European-American $(\mathrm{n}=23)$ & 124 & 71 & $31.07(0.3466)$ \\
\hline Total & 275 & 101 & \\
\hline b $\quad P L G$ & & & $17.18(0.26)$ \\
African-American $(\mathrm{n}=24)$ & 173 & 83 & $14.48(1.43)$ \\
European-American $(\mathrm{n}=23)$ & 111 & 77 & \\
\hline Total & 193 & 99 & \\
\hline \multicolumn{2}{c}{$\mathrm{S}=$ Number of diallelic sites; MAF $=$ minor allele frequency. } \\
\hline
\end{tabular}

874-bp fragment of the human kringle IV-2 repeats. PCR product was purified from an agarose gel using the QIAquick gel extraction kit (QIAGEN). $200 \mathrm{ng}$ of the probe DNA and $10 \mathrm{ng}$ of lambda DNA were labeled with ${ }^{32} \mathrm{P}$-dCTP using the Megaprime DNA labeling system (GE Healthcare, RPN1606). The membranes were pre-hybridized with $15 \mathrm{ml}$ hybridization buffer $\left(0.5 \mathrm{M} \mathrm{NaHPO}_{4}\right.$, $\mathrm{pH} 7.5,1 \mathrm{~mm}$ EDTA, and 7\% SDS) for $2 \mathrm{~h}$ at $50^{\circ} \mathrm{C}$ and then incubated with denatured ${ }^{32} \mathrm{P}$-labeled probe DNA in $25 \mathrm{ml}$ hybridization buffer at $50^{\circ} \mathrm{C}$ overnight, followed by a series of washes with $100 \mathrm{ml} 2 \times \mathrm{SSC}$ and $1 \% \mathrm{SDS}$ at room temperature for $15 \mathrm{~min}, 500$ $\mathrm{ml} 1 \times \mathrm{SSC}$ and $1 \% \mathrm{SDS}$ at $58^{\circ} \mathrm{C}$ for $30 \mathrm{~min}$, and $500 \mathrm{ml} 0.5 \times \mathrm{SSC}$ and $1 \% \mathrm{SDS}$ at $58^{\circ} \mathrm{C}$ for $30 \mathrm{~min}$. The membranes were exposed to Kodak X-ray films overnight at $-80^{\circ} \mathrm{C}$. The X-ray films were developed and the hybridized bands were sized using the Multi-Imager software (BioRad).

\section{Statistical Analysis}

Tajima's D was calculated according to Tajima [34]. Pair-wise linkage disequilibrium was calculated for diallelic sites $>10 \%$ MAF using $\mathrm{r}^{2}$ available on the Genome Variation Server (http:// gvs.gs.washington.edu/GVS/). Linkage disequilibrium between diallelic sites and kringle copy number was also calculated for repeat sizes with $>10 \%$ frequency in the African-American (repeats 10, 11, 14, and 15) and European-Americans (repeats 10, 15, and 16) samples by dichotomizing the repeat allele distribution as either having the repeat or not for each allele. Sequence conservation across species was explored using the Evolutionary Conserved Region (ECR) Browser (http://ecrbrowser.dcode.org/) at default settings and the VISTA Browser (http://genome.lbl.gov/ vista/index.shtml).

\section{Results}

\section{Kringle Copy Number}

The LPA kringle repeat was genotyped in 24 AfricanAmerican and 23 European-American samples. Among the African-American samples, the mean and median kringle copy number was 13.5 and 20, and the copy number ranged from 6 to 25 repeats. The European-American samples were similar with respect to mean and median copy number (13.6 and 23) and range (5 to 22). The most frequent copy number was 16 for the European-Americans representing $20 \%$ of the chromosomes for that sample. For African-Americans, the copy numbers 10 and 14 were equally frequent in that sample each representing $13 \%$ of the chromosomes assayed. As expected based on the existing literature [35-37], both populations had high heterozygosities for the kringle copy number: 0.90 for the European-American sample and 0.91 for the AfricanAmerican sample.

\section{Sequence Diversity of LPA}

Among the 47 samples re-sequenced, a total of 275 diallelic markers were annotated in $56,071 \mathrm{bp}$ of sequence resulting in an average density of one diallelic marker every 204 bp (table 1a). Only 87 (31.64\%) of the markers annotated here have previously been reported in dbSNP (Build 126). This collection of diallelic markers consists of both single nucleotide polymorphisms (95.6\%) and insertion-deletion polymorphisms (4.4\%). The 12 insertion-deletions annotated with $L P A$ range in size from 1 to $4 \mathrm{bp}$ with a mean (median) size of $2 \mathrm{bp}$ ( $3 \mathrm{bp}$ ). The density of diallelic markers as well as the size distribution of insertion-deletions is consistent with previously described candidate genes [38, 39].

As expected, the African-American sample had a greater number of diallelic markers (232) compared with the European-American sample (124), and approximately $30 \%$ of the markers shared between the two samples (table 1a). Nucleotide diversity (as measured by $\pi$ ) was also higher in the African-American sample compared with the European-American sample (table 1a). Both the African-American and the European-American sample had Tajima's D values consistent with neutrality [40].

In comparing the allele frequencies of the $L P A$ markers between European-American and African-American samples, we find that there are 26 high frequency (MAF $>10 \%$ ) markers in the African-American sample that are monomorphic in the European-American sample (supplementary fig. 1 (www.karger.com/doi/10.1159/ 000143403). At the extreme, intronic LPA SNPs 76022 (rs7755463) and 79217 (rs10601217) both have a minor allele frequency of 0.38 in the African-American sample and are monomorphic in the European-American sample. Conversely, three LPA markers are common among the European-American sample but monomorphic in the 
Table 2. Coding variation in $L P A$

\begin{tabular}{|c|c|c|c|c|c|c|}
\hline Site $^{1}$ (residue) & $\begin{array}{l}\text { Nucleotide change } \\
\text { (rs number) }\end{array}$ & $\begin{array}{l}\text { Amino acid } \\
\text { change }\end{array}$ & $\begin{array}{l}\text { Allele freq. } \\
\text { (AA) }\end{array}$ & $\begin{array}{l}\text { Allele freq. } \\
\text { (EA) }\end{array}$ & $\begin{array}{l}\text { Predicted effect } \\
\text { (PolyPhen) }\end{array}$ & $\begin{array}{l}\text { Predicted effect } \\
\text { (SIFT) }\end{array}$ \\
\hline $60672(892)$ & $A>G$ & Ser to Gly & 0.02 & 0.00 & benign & tolerated \\
\hline $66185(990)$ & $\mathrm{G}>\mathrm{A}$ & Arg to Gln & 0.00 & 0.04 & possibly damaging & intolerant \\
\hline 77653 (1298) & $\mathrm{G}>\mathrm{C}$ & Trp to Ser & 0.02 & 0.00 & probably damaging & intolerant \\
\hline 80733 (1349) & $\mathrm{G}>\mathrm{A}$ & Thr to Thr & 0.07 & 0.00 & $\mathrm{n} / \mathrm{a}$ & $\mathrm{n} / \mathrm{a}$ \\
\hline 80758 (1358) & $\mathrm{C}>\mathrm{G}^{2}(\mathrm{rs} 7765803)$ & Leu to Val & 0.58 & 0.36 & benign & tolerated \\
\hline $80800(1372)$ & $\mathrm{C}>\mathrm{G}^{3}(\mathrm{rs7765781})$ & Leu to Val & 0.57 & 0.36 & benign & tolerated \\
\hline 82124 (1399) & $\mathrm{A}>\mathrm{C}^{4}$ & Thr to Pro & 0.04 & 0.15 & possibly damaging & intolerant \\
\hline $82191(1421)$ & $\mathrm{G}>\mathrm{A}^{4}$ & Arg to Gln & 0.02 & 0.02 & benign & tolerated \\
\hline $90066(1523)$ & $\mathrm{T}>\mathrm{C}^{5}$ & Cys to Cys & 0.02 & 0.00 & $\mathrm{n} / \mathrm{a}$ & $\mathrm{n} / \mathrm{a}$ \\
\hline $109817(1586)$ & $\mathrm{G}>\mathrm{A}$ & Val to Ile & 0.03 & 0.00 & benign & tolerated \\
\hline $109854(1598)$ & $\mathrm{T}>\mathrm{C}^{5}$ & Met to Thr & 0.05 & 0.00 & benign & tolerated \\
\hline $118667(1679)$ & $\mathrm{C}>\mathrm{T}^{6}(\mathrm{rs} 1801693)$ & Thr to Met & 0.14 & 0.39 & benign & tolerated \\
\hline 118757 (1709) & $\mathrm{T}>\mathrm{A}$ & Val to Asp & 0.02 & 0.00 & benign & tolerated \\
\hline $119328(1719)$ & $\mathrm{C}>\mathrm{T}$ & Asp to Asp & 0.09 & 0.00 & $\mathrm{n} / \mathrm{a}$ & $\mathrm{n} / \mathrm{a}$ \\
\hline $119421(1750)$ & $\mathrm{T}>\mathrm{C}$ & His to His & 0.02 & 0.00 & $\mathrm{n} / \mathrm{a}$ & $\mathrm{n} / \mathrm{a}$ \\
\hline $121754(1776)$ & $\mathrm{C}>\mathrm{T}$ & Asp to Asp & 0.03 & 0.00 & $\mathrm{n} / \mathrm{a}$ & $\mathrm{n} / \mathrm{a}$ \\
\hline $121755(1777)$ & $A>G$ & Ile to $\mathrm{Val}$ & 0.03 & 0.00 & benign & tolerated \\
\hline $124522(1822)$ & $\mathrm{G}>\mathrm{C}$ & Gly to Ala & 0.08 & 0.00 & benign & tolerated \\
\hline $135459(2016)$ & $\mathrm{C}>\mathrm{T}$ & Arg to Cys & 0.18 & 0.25 & probably damaging & intolerant \\
\hline $\begin{array}{l}\text { AA }=\text { Africa } \\
{ }^{1} \text { SNPs are } \mathrm{n} \\
{ }^{2} \text { Kringle IV } \\
{ }^{3} \text { Kringle IV } \\
{ }^{4} \text { Kringle IV } \\
{ }^{5} \text { Kringle IV } \\
{ }^{6} \text { Kringle IV }\end{array}$ & $\begin{array}{l}\text { merican; EA = Europ } \\
\text { ered based on the Ge } \\
\text { e } 7 \text { polymorphisms or } \\
\text { e } 8 \text { polymorphism or } \\
\text { e } 8 \text { polymorphism or } \\
\text { e } 9 \text { polymorphisms or } \\
\text { polymorphism origin }\end{array}$ & $\begin{array}{l}\text {-American; fr } \\
\text { ank accession } \\
\text { nally describe } \\
\text { ally described } \\
\text { ally described } \\
\text { nally describe } \\
\text { described by }\end{array}$ & $\begin{array}{l}\text { frequency. } \\
\text { nber DQ452 } \\
\text { Prins et al. } \\
\text { Prins et al. [6 } \\
\text { Ogorelkova } \\
\text { Ogorelkova } \\
\text { der Hoek et }\end{array}$ & $\begin{array}{l} \\
\text { l. [53]. } \\
\text { al. [53]. } \\
\text { [65] and K }\end{array}$ & 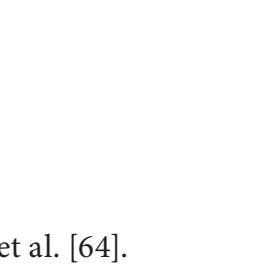 & \\
\hline
\end{tabular}

African-American sample. In comparing allele frequencies between the two population samples for $275 \mathrm{LPA}$ markers, 30 SNPs had a MAF difference of $\geq 17 \%$, and this MAF difference is statistically significant for each SNP comparison at $p<0.01$. Two SNPs had a MAF difference of $>35 \%$ between the two population samples, and this difference is statistically significant at $p<0.0001$ for these two SNP comparisons. Overall, the correlation $\left(\mathrm{R}^{2}\right)$ between European-American and African-American sample allele frequencies at $L P A$ is 0.58 , which is higher compared with an earlier estimate of 0.37 in an analysis of 50 candidate genes in the same two population samples [41].

Nineteen coding SNPs were annotated in LPA, 14 of which were nonsynonymous (table 2). Typically, the average candidate gene has an equal [39] or fewer [42] number of nonsynonymous SNPs compared with synonymous SNPs. The overall observed ratio of nonsynonymous to synonymous substitutions in this study was $2.8: 1$. For African-Americans, the observed ratio was 2.6:1 while the observed ratio in European-Americans was 7:0. If the expectation is that half of the coding SNPs are nonsynonmyous (that is, a ratio of 1:1 for each population sample), the observed ratio of nonsynonymous and synonymous SNPs in the African-American sample is not significantly different from expected (Fisher's exact; $p=0.305$ ). However, for the European-American sample, there is evidence that an excess of nonsynonymous SNPs may exist compared with that expected (Fisher's exact $\mathrm{p}=$ 0.059).

\section{Linkage Disequilibrium within LPA}

To describe linkage disequilibrium (LD) across $L P A$, we first calculated pair-wise $\operatorname{LD}\left(\mathrm{r}^{2}\right)$ for all SNPs with a MAF $>10 \%$ for each population sample (table 3). As expected based on population history and demography [43], the European-American sample in general had a greater proportion of SNP comparisons with perfect (approximately $7 \%$ ) or strong (12\%) LD compared with the African-American sample. Likewise, the proportion of 
Table 3. Strength of linkage disequilibrium $\left(\mathrm{r}^{2}\right)$ for common SNPs (minor allele frequency $>10 \%$ ) in $L P A$ and across $L P A / P L G$ in African-Americans and European-Americans

\begin{tabular}{|c|c|c|c|c|c|c|c|c|}
\hline \multirow[t]{2}{*}{ Gene(s) } & \multicolumn{4}{|c|}{ African-Americans $(\mathrm{n}=24)$} & \multicolumn{4}{|c|}{ European-Americans $(\mathrm{n}=23)$} \\
\hline & $\begin{array}{l}\text { \# pair-wise } \\
\text { comparisons }\end{array}$ & $\begin{array}{l}\text { perfect } \\
\text { LD }^{1}\end{array}$ & $\begin{array}{l}\text { strong } \\
\mathrm{LD}^{2}\end{array}$ & $\begin{array}{l}\text { weak } \\
\mathrm{LD}^{3}\end{array}$ & $\begin{array}{l}\text { \# pair-wise } \\
\text { comparisons }\end{array}$ & $\begin{array}{l}\text { perfect } \\
\text { LD }^{1}\end{array}$ & $\begin{array}{l}\text { strong } \\
\mathrm{LD}^{2}\end{array}$ & $\begin{array}{l}\text { weak } \\
\mathrm{LD}^{3}\end{array}$ \\
\hline$L P A$ & 2,926 & $6 \%$ & $9 \%$ & $40 \%$ & 2,485 & $7 \%$ & $12 \%$ & $24 \%$ \\
\hline$L P A / P L G$ & 15,225 & $2 \%$ & $3 \%$ & $7 \%$ & 10,878 & $4 \%$ & $9 \%$ & $35 \%$ \\
\hline
\end{tabular}

SNP comparisons with low LD (24\%) was lower than that observed for the African-descent population.

\section{Linkage Disequilibrium between LPA and PLG}

Plasminogen (PLG) immediately flanks $L P A$ with only $\sim 40 \mathrm{~kb}$ of sequence between the two genes. Because $L P A$ is transcribed in the opposite direction compared with $P L G$, it is feasible that the two genes share a common regulatory element such as the transcription control region located between PLG and LPA [44-46]. Also, given the proximity of the two genes, LPA SNPs may be in strong LD with PLG SNPs, a factor that will affect the interpretation of genetic association studies correlating specific genetic variants to human disease or phenotypes. Because of the potential influence of PLG on LPA association studies, it is useful to characterize the LD structure of the genomic sequence that contains both $L P A$ and PLG. To do this, we first re-sequenced and characterized genetic variation in $P L G$ and the sequence between $L P A$ and PLG among the same samples characterized for LPA (23 European-Americans and 24 African-Americans). We then calculated pair-wise $\mathrm{LD}\left(\mathrm{r}^{2}\right)$ across the region containing both $L P A$ and $P L G$.

In re-sequencing $24,465 \mathrm{bp}$ of the sequence for $P L G$, a total of 193 diallelic sites were annotated in the European- and African-American samples combined (table 1b). Like $L P A$, the African-American sample had more sites (173) compared with the European-American sample (111), and the resulting estimates of nucleotide diversity for both population samples was consistent with neutrality (table 1 b). PLG had nearly equal numbers of synonymous (10) and nonsynonymous (7) SNPs in the combined samples, and neither the African-American nor European-American sample had a significant excess of nonsynonymous SNPs (5 and 3, respectively) compared with synonymous SNPs (3 and 8, respectively) in PLG.
We calculated pair-wise $\operatorname{LD}\left(\mathrm{r}^{2}\right)$ for the combined LPA/ $P L G$ datasets for each population sample separately for all common SNPs (MAF $>10 \%$; fig. 2 and table 3). For the African-American sample, none of the LPA SNPs were in strong LD with PLG SNPs. Unlike the African-American sample, the European-American sample did have a few LPA SNPs in strong LD with PLG SNPs. More specifically PLG SNPs 1412 (rs4252051) and 1417 (rs4252052) were correlated with or 'tagged' PLGSNP 1470 (rs4252053) and $L P A$ SNPs 3264, 17836, 73803, and 82124. Interestingly, PLG SNP 1470 and LPA SNP 82124 were $116 \mathrm{~kb}$ apart, and the latter SNP was a nonsynonymous SNP in $L P A$ exon 6 while the former SNP (as well as the other two $P L G$ SNPs) was in the PLG 5' flanking region that is conserved with rhesus macaque.

\section{Association between LPA and PLG SNPs and Kringle Copy Number \\ There is a well-established inverse relationship between} the highly variable kringle size polymorphism and Lp(a) levels in humans [47-49]. Not so well-established are associations between specific LPA SNPs and Lp(a) levels in humans. For the few reported studies with significant associations between LPA SNPs and Lp(a) levels [50-54] or clinical phenotypes [55-57], none has had the complete or near complete LPA sequence data to assess whether or not the genotyped SNP is in LD with kringle IV-2 repeat copy number in their population sample. Thus, it is unclear whether an LPA SNP associated with $\mathrm{Lp}$ (a) levels is due the well-established association between the kringle IV-2 repeat polymorphism and Lp(a) levels or a novel SNP association. Because we have both re-sequencing data for SNP discovery and kringle copy number in the same samples, we are able to establish whether or not kringle copy number is associated with specific LPA or PLG SNPs in European- or African-Americans. 


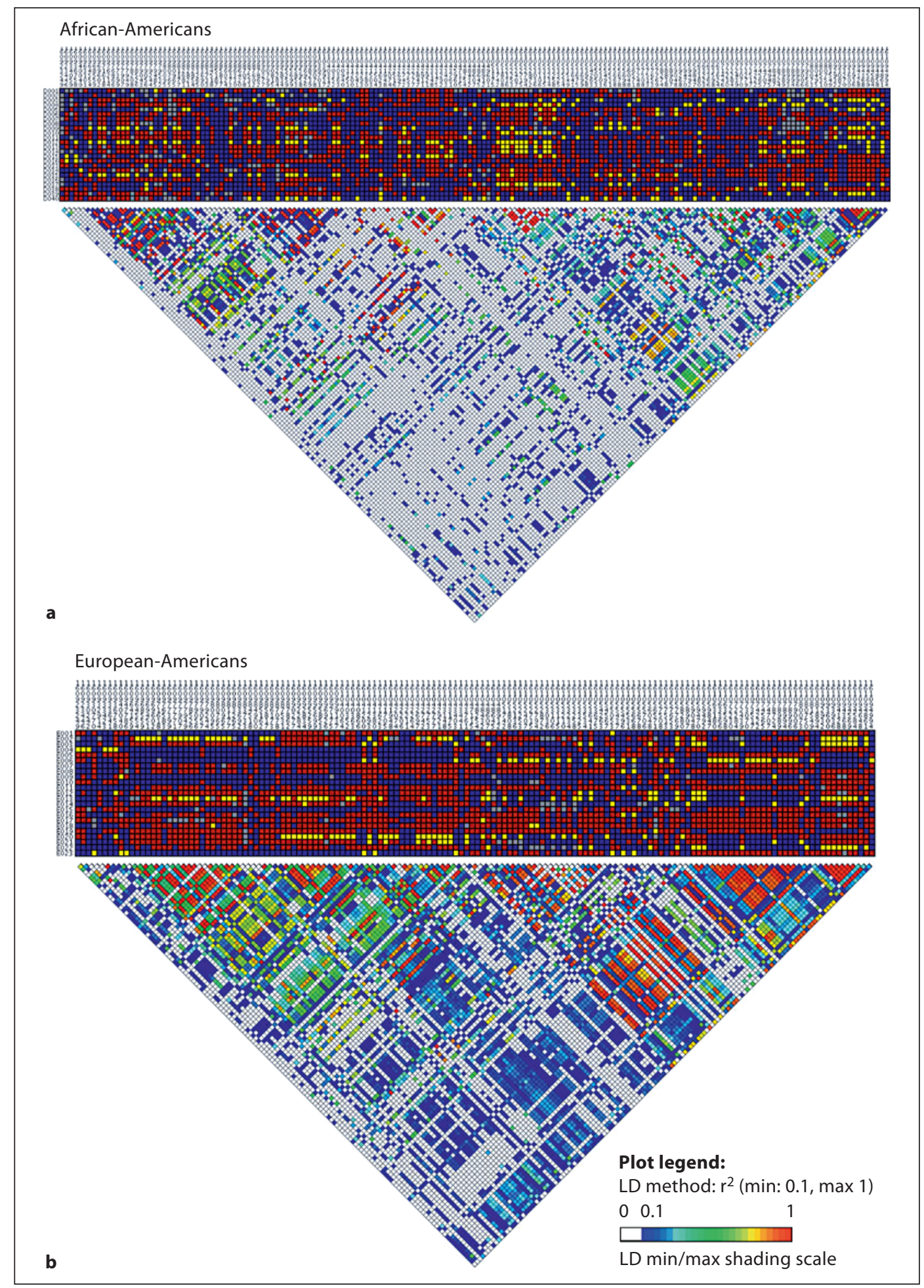

Fig. 2. Pair-wise linkage disequilibrium $\left(\mathrm{r}^{2}\right)$ calculated across $L P A$ and PLG in two populations. Common SNPs (minor allele frequency $>10 \%$ ) are numbered across the top of the figure, and samples are numbered to the left side of the figure. SNPs are numbered according to their chromosomal position based on NCBI Build 36. Each square represents the individual's genotype for a specific SNP, and each square is color-coded so that blue represents being homozygous for the common allele, red represents being heterozygous, and yellow represents being homozygous for the rare allele. Gray represents missing data. a African-Americans. b European-Americans. 
Since the kringle polymorphism is multi-allelic, we dichotomized the repeat distribution as having the repeat or not for common repeats (frequency $>10 \%$ ) in either the African-American or European-American samples. In the African-American sample, no kringle repeat was in strong $L D\left(r^{2} \geq 0.80\right)$ with any $L P A$ or PLG SNPs in this dataset. The highest $\mathrm{r}^{2}$ in African-Americans was 0.57 for kringle repeat 14 and LPA SNP 72373. Similar to the African-American population, no kringle repeat was in strong LD with either LPA or PLG SNPs in the EuropeanAmerican samples. The highest $\mathrm{r}^{2}$ in European-Americans was 0.42 for kringle repeat 10 and LPA SNP 74970. Thus, for either population sample, no single $L P A$ or $P L G$ SNP was in strong LD with specific kringle copy number polymorphisms.

\section{Discussion}

We describe here the first in-depth characterization of the natural sequence variation present in the candidate gene $L P A$ and its relationship with the well-known, highly polymorphic kringle IV-2 repeat. Previous reports of SNP discovery in LPA have been published; however, many of these reports describe only a fraction of natural variation in the $L P A$ reference sequence. The majority of reports, in fact, concentrated polymorphism discovery efforts to the promoter $/ 5^{\prime}$ upstream region [58-61] or to coding regions of $L P A[52,53,62-70]$. A few SNPs in the intronic or flanking region of $L P A$ have also been described [71].

In re-sequencing 47 presumably healthy individuals (23 European-Americans and 24 African-Americans), we discovered and characterized vastly more $L P A$ variation compared with that published in the current literature or reported in dbSNP (Build 126). Based on previous SNP discovery efforts using the same DNA samples and subsequent large-scale genotyping efforts in various U.S. populations [30-33], we expect that these results are representative for Americans of European- and African-descent. These data, although unlinked to either Lp(a) levels or cardiovascular phenotypes, are important and necessary for the study of $L p(a)$ 's role in human disease for several reasons. First, as described above, all published variation discovery efforts for LPA save for two $[50,53]$ included only European-descent populations. Given the well-known difference in $\mathrm{Lp}(\mathrm{a})$ levels between these two populations [16, 23], our data can serve as the foundation in understanding these differences at the DNA sequence level. Indeed, we demonstrate that only $30 \%$ of $L P A$ SNPs are shared between the two samples, and we have identified several high-frequency SNPs in the African-American sample that are monomorphic in the EuropeanAmerican sample warranting further study in samples linked to phenotypes. Also, within populations, these data can help determine why LPA kringle IV-2 alleles with the same size are associated with very different $L p(a)$ levels among unrelated individuals [71, 72].

Second, these data provide the genotype data for $L P A$ and $P L G$ variation necessary for calculating linkage disequilibrium within these candidate genes as well as across the genomic region containing both these genes. Similar to previous reports [37], we do find strong pair-wise linkage disequilibrium for SNPs found on relatively opposite ends of LPA. In general, though, we find that most LPA pair-wise comparisons for either European-American or African-American sample resulted in moderate to weak $\mathrm{LD}$ (fig. 1). Also, we found that $L P A$ is not in strong linkage disequilibrium with its neighboring relative, PLG. Finally, contrary to previous reports [64], specific $L P A$ SNPs are not correlated with specific LPA kringle IV-2 copy numbers. Kraft and colleagues [64] presented evidence for linkage disequilibrium between LPA SNP 118667 (Met to Thr) and kringle repeat 18 in a sample of Austrians. In our European-American dataset, kringle repeat 18 occurred at a frequency of only $4 \%$ and was excluded from the calculations. LPA SNP 118667 is not in strong linkage disequilibrium with the kringle repeats 10, 15, and 16 in the European-American sample tested here $\left(r^{2}=0.10,0.04\right.$, and 0.01 , respectively).

The characterization of linkage disequilibrium and the inclusion of the kringle IV-2 copy number variation are necessary for the interpretation of previous LPA genetic association studies. For example, Kraft et al. [54] reported a significant association with the $+93 \mathrm{C} / \mathrm{T}$ polymorphism (LPA SNP 2995; rs1853021) and Lp(a) concentrations in Africans but not Europeans. The lack of association in the European population has often been interpreted as a consequence of the linkage disequilibrium between $+93 \mathrm{C} / \mathrm{T}$ polymorphism and intermediate size kringle IV-2 repeats in that population [54]. We offer an alternative explanation: the $+93 \mathrm{C} / \mathrm{T}$ polymorphism in African-Americans is in linkage disequilibrium $\left(\mathrm{r}^{2}=1\right)$ with the nonsynonymous 77653 (Trp to Ser), among other LPA SNPs, described here (table 2). LPA SNP 77653 was predicted by SIFT and PolyPhen to be intolerant/probably damaging and was not found among EuropeanAmericans. In contrast, no nonsynonymous or potentially functional SNPs were in linkage disequilibrium with $+93 \mathrm{C} / \mathrm{T}$ polymorphism in the European-American sam- 
ple presented here. Based on these new data, we propose that the association with the $+93 \mathrm{C} / \mathrm{T}$ polymorphism and $L p(a)$ levels in Africans may be due to the nonsynonymous LPA SNP 77653. Further LPA SNP discovery efforts in diverse populations will be needed to interpret and design studies that include individuals of other racial/ethnic backgrounds [37, 73].

Despite the amount of sequence represented in this study, a weakness of this approach lies in the fact that we did not attempt to re-sequence the LPA kringle IV-2 repeat region for variation discovery as it was difficult to locate enough unique sequence for successful primer design. Based on previous reports of sequence conservation in European-descent populations [52, 62, 70], we do not expect the lack of coverage in this area to significantly impact our overall analyses and conclusions. Because there are no data available on kringle IV-2 repeat variation in African-descent populations, we cannot predict whether or not the addition of this information would alter our conclusions drawn for the African-American samples here.

Other limitations include the fact that only a small proportion of the sequence scanned for variation discovery includes flanking sequence for either $L P A$ or $P L G$. Thus, there could be SNPs distal to these re-sequenced flanking regions that are in strong LD with $L P A$ or PLG SNPs or kringle copy numbers. Finally, this study is limited to a small sample of European-Americans and African-Americans. While the study is powered to detect common genetic variation, the study is underpowered to detect SNPs with minor allele frequencies between 1 and $5 \%$ [74]. Further re-sequencing in greater numbers of individuals is required to complete the catalogue of rare genetic variations $[75,76]$.

Despite these limitations, we were able to catalogue common variation in $L P A$ and PLG in the same DNA samples and describe the level of linkage disequilibrium between both of these candidate genes important in cardiovascular research. We also demonstrate that kringle copy number variation in $L P A$ is not in strong linkage disequilibrium with LPA or PLG SNPs, which provides invaluable data for the interpretation of association studies for these candidate genes. Collectively, these data demonstrate that similar to the genome-wide effort of cataloguing and integrating copy-number variation into SNP datasets [77], effort must be made to catalogue and integrate kringle IV-2 repeat polymorphism and sequence variation data for $L P A$ in all populations for future genetic association studies relevant to cardiovascular disease.

\section{Acknowledgements}

We thank Dr. Mark Wurfel and Jeanna Strout (University of Washington) for maintaining the cell lines used in the kringle genotyping. This work was funded by grants from the National Heart, Lung, and Blood Institute's Program for Genomic Applications (U01 HL66682 and U01 HL66728) and the National Institute of Environmental Health Science's Environmental Genome Project (N01 ES15478)

\section{References}

1 Scanu AM: Lp(a) lipoprotein - coping with heterogeneity. N Engl J Med 2003;349:20892090.

2 Koschinsky ML, Cote GP, Gabel B, van der Hoek YY: Identification of the cysteine residue in apolipoprotein(a) that mediates extracellular coupling with apolipoprotein B-100. J Biol Chem 1993;268:19819-19825.

- 3 Kraft HG, Menzel HJ, Hoppichler F, Vogel W, Utermann G: Changes of genetic apolipoprotein phenotypes caused by liver transplantation. Implications for apolipoprotein synthesis. J Clin Invest 1989;83:137-142.

4 White AL, Lanford RE: Cell surface assembly of lipoprotein(a) in primary cultures of baboon hepatocytes. J Biol Chem 1994;269: 28716-28723.
-5 Rotimi CN, Cooper RS, Marcovina SM, McGee D, Owoaje E, Ladipo M: Serum distribution of lipoprotein(a) in African Americans and Nigerians: Potential evidence for a genotype-environmental effect. Genet Epidemiol 1997;14:157-168.

6 Marcovina SM, Gaur VP, Albers JJ: Biological variability of cholesterol, triglyceride, low- and high-density lipoprotein cholesterol, lipoprotein(a), and apolipoproteins A- I and B. Clin Chem 1994;40:574-578.

7 Cobbaert C, Arentsen JC, Mulder P, Hoogerrugge N, Lindemans J: Significance of various parameters derived from biological variability of lipoprotein(a), homocysteine, cysteine, and total antioxidant status. Clin Chem 1997;43:1958-1964.
-8 Marcovina SM, Koschinsky ML, Albers JJ, Skarlatos S: Report of the National Heart, Lung, and Blood Institute workshop on lipoprotein(a) and cardiovascular disease: recent advances and future directions. Clin Chem 2003;49:1785-1796.

-9 McLean JW, Tomlinson JE, Kuang WJ, Eaton DL, Chen EY, Fless GM, Scanu AM, Lawn RM: cDNA sequence of human apolipoprotein(a) is homologous to plasminogen. Nature 1987;330:132-137.

10 Boffelli D, Cheng J-F, Rubin EM: Convergent evolution in primates and an insectivore. Genomics 2004;83:19-23.

11 Boerwinkle E, Leffert CC, Lin J, Lackner C, Chiesa G, Hobbs HH: Apolipoprotein(a) gene accounts for greater than $90 \%$ of the variation in plasma lipoprotein(a) concentrations. J Clin Invest 1992;90:52-60. 
12 Boomsma DI, de Knijff P, Labeur C, Martin NG, Havekes LM, Princen HMG: The effect of apolipoprotein(a)-, apolipoprotein E-, and apolipoprotein A4-polymorphisms on quantitative lipoprotein(a) concentrations. Twin Res 2000;3:152-158.

-13 Kraft HG, Lingenhel A, Pang RW, Delport R, Trommsdorff $M$, Vermaak $H$, Janus ED, Utermann G: Frequency distributions of apolipoprotein(a) kringle IV repeat alleles and their effects on lipoprotein(a) levels in Caucasian, Asian, and African populations: The distribution of null alleles is non-random. Eur J Hum Genet 1996;4:74-87.

- 14 Schmidt K, Kraft HG, Parson W, Utermann G: Genetics of the Lp(a)/apo(a) system in an autochthonous Black African population from the Gabon. Eur J Hum Genet 2006; 14: 190-201.

-15 Ali S, Bunker CH, Aston CE, Ukoli FA, Kamboh MI: Apolipoprotein A kringle 4 polymorphism and serum lipoprotein(a) concentrations in African blacks. Hum Biol 1998; 70:477-490.

-16 Marcovina SM, Albers JJ, Jacobs DR Jr, Perkins LL, Lewis CE, Howard BV, Savage P: Lipoprotein[a] concentrations and apolipoprotein[a] phenotypes in Caucasians and African Americans. The CARDIA study. Arterioscler Thromb 1993;13:1037-1045.

-17 Sandholzer C, Hallman DM, Saha N, Sigurdsson G, Lackner C, Csaszar A, Boerwinkle E, Utermann G: Effects of the apolipoprotein(a) size polymorphism on the lipoprotein(a) concentration in 7 ethnic groups. Hum Genet 1991;86:607-614.

18 Danesh J, Collins R, Peto R: Lipoprotein(a) and coronary heart disease. Meta-analysis of prospective studies. Circulation 2000;102: 1082-1085.

19 Danik JS, Rifai N, Buring JE, Ridker PM: Lipoprotein(a), measured with an assay independent of apolipoprotein(a) isoform size, and risk of future cardiovascular events among initially healthy women. JAMA 2006; 296:1363-1370

-20 Guerra R, Yu Z, Marcovina S, Peshock R, Cohen JC, Hobbs HH: Lipoprotein(a) and apolipoprotein(a) isoforms: no association with coronary artery calcification in the dallas heart study. Circulation 2005;111:14711479.

21 Moliterno DJ, Jokinen EV, Miserez AR, Lange RA, Willard JE, Boerwinkle E, Hillis LD, Hobbs HH: No association between plasma lipoprotein(a) concentrations and the presence or absence of coronary atherosclerosis in African-Americans. Arterioscler Thromb Vasc Biol 1995; 15:850-855.

22 Paultre F, Pearson TA, Weil HFC, Tuck CH, Myerson M, Rubin J, Francis CK, Marx HF, Philbin EF, Reed RG, Berglund L: High levels of $\mathrm{Lp}(\mathrm{a})$ with a small apo(a) isoform are associated with coronary artery disease in African American and white Men. Arterioscler Thromb Vasc Biol 2000;20:2619-2624.
23 Marcovina SM, Albers JJ, Wijsman E, Zhang $\mathrm{ZH}$, Chapman NH, Kennedy H: Differences in $\mathrm{Lp}$ (a) concentrations and apo(a) polymorphs between black and white Americans. J Lipid Res 1996;37:2569-2585.

24 Boerwinkle E, Menzel HJ, Kraft HG, Utermann G: Genetics of the quantitative Lp(a) lipoprotein trait. III. Contribution of $\mathrm{Lp}(\mathrm{a})$ glycoprotein phenotypes to normal lipid variation. Hum Genet 1989;82:73-78.

25 Scholz M, Kraft HG, Lingenhel A, Delport R, Vorster EH, Bickeboller H, Utermann G: Genetic control of lipoprotein(a) concentrations is different in Africans and Caucasians. Eur J Hum Genet 1999;7:169-178.

26 Mooser V, Scheer D, Marcovina SM, Wang J, Guerra R, Cohen J, Hobbs HH: The Apo(a) gene is the major determinant of variation in plasma Lp(a) levels in African Americans. Am J Hum Genet 1997;61:402-417.

27 Barkley RA, Brown AC, Hanis CL, Kardia SL, Turner ST, Boerwinkle E: Lack of genetic linkage evidence for a trans-acting factor having a large effect on plasma lipoprotein[a] levels in African Americans. J Lipid Res 2003;44:1301-1305.

28 Dausset J, Cann H, Cohen D, Lathrop M, Lalouel JM, White R: Centre d'etude du polymorphisme humain (CEPH): collaborative genetic mapping of the human genome. Genomics 1990;6:575-577.

29 Meucci MA, Marsh S, Watters JW, McLeod HL: CEPH individuals are representative of the European American population: implications for pharmacogenetics. Pharmacogenomics 2005;6:59-63.

30 Reiner AP, Carlson CS, Rieder MJ, Siscovick DS, Liu K, Chandler WL, Green D, Schwartz SM, Nickerson DA: Coagulation factor VII gene haplotypes, obesity-related traits, and cardiovascular risk in young women. J Thromb Haemost 2007;5:42-49.

-31 Reiner AP, Carty CL, Carlson CS, Wan JY Rieder MJ, Smith JD, Rice K, Fornage M, Jaquish CE, Williams OD, Tracy RP, Lewis CE, Siscovick DS, Boerwinkle E, Nickerson DA: Association between patterns of nucleotide variation across the three fibrinogen genes and plasma fibrinogen levels: the Coronary Artery Risk Development in Young Adults (CARDIA) study. J Thromb Haemost 2006;4:1279-1287.

32 Carlson CS, Aldred SF, Lee PK, Tracy RP, Schwartz SM, Rieder M, Liu K, Williams OD, Iribarren C, Lewis EC, Fornage $M$, Boerwinkle E, Gross M, Jaquish C, Nickerson DA, Myers RM, Siscovick DS, Reiner AP: Polymorphisms within the C-reactive protein (CRP) promoter region are associated with plasma CRP levels. Am J Hum Genet 2005;77:64-77.
33 Crawford DC, Sanders CL, Qin X, Smith JD, Shephard C, Wong M, Witrak L, Rieder MJ, Nickerson DA: Genetic variation is associated with C-reactive protein levels in the Third National Health and Nutrition Examination Survey. Circulation 12-5-2006;114: 2458-2465.

34 Tajima F: Statistical method for testing the neutral mutation hypothesis by DNA polymorphism. Genetics 1989;123:585.

35 Lackner C, Boerwinkle E, Leffert CC, Rahmig T, Hobbs HH: Molecular basis of apolipoprotein(a) isoform size heterogeneity as revealed by pulsed-field gel electrophoresis. J Clin Invest 1991;87:2077-2086.

36 Gaw A, Boerwinkle E, Cohen JC, Hobbs HH: Comparative analysis of the Apo(a) gene, apo(a) glycoprotein, and plasma concentration of $\mathrm{Lp}(\mathrm{a})$ in three ethnic groups. J Clin Invest 1994;93:2526-2534.

37 Puckey LH, Lawn RM, Knight BL: Polymorphisms in the apolipoprotein(a) gene and their relationship to allele size and plasma lipoprotein(a) concentration. Hum Mol Genet 1997;6:1099-1107.

- 38 Bhangale TR, Rieder MJ, Livingston R, Nickerson DA: Comprehensive identification and characterization of diallelic insertion-deletion polymorphisms in 330 human candidate genes. Hum Mol Genet 2005;14:59.

-39 Crawford DC, Akey DT, Nickerson DA: The patterns of natural variation in human genes. Annu Rev Genomics Hum Genet 2005;6: 287-312.

-40 Biswas S, Akey JM: Genomic insights into positive selection. Trends Genet 2006;22: 437-446.

41 Carlson CS, Eberle MA, Rieder MJ, Smith JD, Kruglyak L: Additional SNPs and linkage-disequilibrium analyses are necessary for whole-genome association studies in humans. Nat Genet 2003;33:518

42 Cargill M, Altshuler D, Ireland J, Sklar P, Ardlie K: Characterization of single-nucleotide polymorphisms in coding regions of human genes. Nat Genet 1999;22:231.

43 Reich DE, Cargill M, Bolk S, Ireland J, Sabeti PC: Linkage disequilibrium in the human genome. Nature 2001;411:199.

44 Yang Z, Boffelli D, Boonmark N, Schwartz K, Lawn R: Apolipoprotein(a) gene enhancer resides within a LINE element. J Biol Chem 1998;273:891-897.

45 Huby T, Afzal V, Doucet C, Lawn RM, Gong EL, Chapman MJ, Thillet J, Rubin EM: Regulation of the expression of the apolipoprotein(a) gene: Evidence for a regulatory role of the $5^{\prime}$ distal apolipoprotein(a) transcription control region enhancer in yeast artificial chromosome transgenic mice. Arterioscler Thromb Vasc Biol 2003;23:1633-1639.

-46 Wade DP, Puckey LH, Knight BL, Acquati F, Mihalich A, Taramelli R: Characterization of multiple enhancer regions upstream of the apolipoprotein(a) gene. J Biol Chem 1997; 272:30387-30399. 
\47 Kraft HG, Kochl S, Menzel HJ, Sandholzer C, Utermann G: The apolipoprotein(a) gene: A transcribed hypervariable locus controlling plasma lipoprotein(a) concentration. Hum Genet 1992;90:220-230.

- 48 Utermann G, Menzel HJ, Kraft HG, Duba HC, Kemmler HG, Seitz C: Lp(a) glycoprotein phenotypes. Inheritance and relation to $\mathrm{Lp}$ (a)-lipoprotein concentrations in plasma. J Clin Invest 1987;80:458-465.

-49 Gavish D, Azrolan N, Breslow JL: Plasma $\mathrm{Lp}$ (a) concentration is inversely correlated with the ratio of kringle IV/kringle $V$ encoding domains in the apo(a) gene. J Clin Invest 1989;84:2021-2027.

-50 Chretien JP, Coresh J, Berthier-Schaad Y, Kao WH, Fink NE, Klag MJ, Marcovina SM, Giaculli F, Smith MW: Three single-nucleotide polymorphisms in LPA account for most of the increase in lipoprotein(a) level elevation in African Americans compared with European Americans. J Med Genet 2006;43: 917-923.

-51 Suzuki K, Kuriyama M, Saito T, Ichinose A: Plasma lipoprotein(a) levels and expression of the apolipoprotein(a) gene are dependent on the nucleotide polymorphisms in its $5^{\prime}$ flanking region. J Clin Invest 1997;99:13611366.

-52 Mancini FP, Mooser V, Guerra R, Hobbs HH: Sequence microheterogeneity in apolipoprotein(a) gene repeats and the relationship to plasma Lp(a) levels. Hum Mol Genet 1995; 4:1535-1542.

-53 Ogorelkova M, Kraft HG, Ehnholm C, Utermann G: Single nucleotide polymorphisms in exons of the apo(a) kringles IV types 6 to 10 domain affect $L p(a)$ plasma concentrations and have different patterns in Africans and Caucasians. Hum Mol Genet 2001;10: 815-824.

54 Kraft HG, Windegger M, Menzel HJ, Utermann G: Significant impact of the $+93 \mathrm{C} / \mathrm{T}$ polymorphism in the apolipoprotein(a) gene on $\mathrm{Lp}$ (a) concentrations in Africans but not in Caucasians: confounding effect of linkage disequilibrium. Hum Mol Genet 1998;7:257264.

55 Ichinose A, Kuriyama M: Detection of polymorphisms in the 5 -flanking region of the gene for apolipoprotein(a). Biochem Biophys Res Comm 1995;209:372-378.

56 Luke MM, Kane JP, Liu DM, Rowland CM, Shiffman D, Cassano J, Catanese JJ, Pullinger CR, Leong DU, Arellano AR, Tong CH, Movsesyan I, Naya-Vigne J, Noordhof C, Feric NT, Malloy MJ, Topol EJ, Koschinsky ML, Devlin JJ, Ellis SG: A Polymorphism in the protease-like domain of apolipoprotein(a) is associated with severe coronary artery disease. Arterioscler Thromb Vasc Biol 2007;27:2030-2036.
57 Simo JM, Joven J, Vilella E, Ribas M, Figuera L, Virgos C, Sundaram IM, Hoover-Plow J: Polymorphisms in human apolipoprotein(a) kringle IV-10 and coronary artery disease: Relationship to allele size, plasma lipoprotein(a) concentration, and lysine binding activity. J Mol Med 2001;79:294-299.

58 Wade DP, Clarke JG, Lindahl GE, Liu AC, Zysow BR, Meer K, Schwartz K, Lawn RM: 5' control regions of the apolipoprotein(a) gene and members of the related plasminogen gene family. Proc Natl Acad Sci USA 1993. 90:1369-1373

$59 \mathrm{Wu}$ JH, Lee IN: Studies of apolipoprotein (a) promoter from subjects with different plasma lipoprotein (a) concentrations. Clin Biochem 2003;36:241-246.

60 Zysow BR, Lindahl GE, Wade DP, Knight BL Lawn RM: C/T polymorphism in the $5^{\prime}$ untranslated region of the apolipoprotein(a) gene introduces an upstream ATG and reduces in vitro translation. Arterioscler Thromb Vasc Biol 1995;15:58-64.

61 Puckey LH, Knight BL: Sequence and functional changes in a putative enhancer region upstream of the apolipoprotein(a) gene. Atherosclerosis 2003;166:119-127.

62 Rosby O, Alestrom P, Berg K: High-degree sequence conservation in LPA kringle IVtype 2 exons and introns. Clin Genet 1997; 52:293-302.

63 Prins J, Leus FR, Bouma BN, van Rijn HJ: The identification of polymorphisms in the coding region of the apolipoprotein(a) gene. Thromb Haemost 1999;82:1709-1717.

64 Kraft HG, Haibach C, Lingenhel A, Brunner C, Trommsdorff M, Kronenberg F, Muller HJ, Utermann G: Sequence polymorphism in kringle IV 37 in linkage disequilibrium with the apolipoprotein(a) size polymorphism. Hum Genet 1995;95:275-282.

65 van der Hoek YY, Wittekoek ME, Beisiegel U, Kastelein JJ, Koschinsky ML: The apolipoprotein(a) kringle IV repeats which differ from the major repeat kringle are present in variably-sized isoforms. Hum Mol Genet 1993;2:361-366.

-66 Scanu AM, Pfaffinger D, Lee JC, Hinman J: A single point mutation (Trp72 $\rightarrow$ Arg) in human apo(a) kringle 4-37 associated with a lysine binding defect in $\mathrm{Lp}(\mathrm{a})$. Biochim Biophys Acta 1994;1227:41-45.

67 Prins J, Leus FR, van der Hoek YY, Kastelein JJ, Bouma BN, van Rijn HJ: The identification and significance of a Thr $\rightarrow$ Pro polymorphism in kringle IV type 8 of apolipoprotein(a). Thromb Haemost 1997;77:949954.

68 Ogorelkova M, Gruber A, Utermann G: Molecular basis of congenital lp(a) deficiency: A frequent apo(a) 'null' mutation in Caucasians. Hum Mol Genet 1999;8:2087-2096.
69 Parson W, Kraft HG, Niederstatter H, Lingenhel AW, Kochl S, Fresser F, Utermann G: A common nonsense mutation in the repetitive Kringle IV-2 domain of human apolipoprotein(a) results in a truncated protein and low plasma Lp(a). Hum Mutat 2004;24: 474-480.

70 Rosby O, Alestrom P, Berg K: Sequence conservation in kringle IV-type 2 repeats of the LPA gene. Atherosclerosis 2000;148:353364.

71 Cohen JC, Chiesa G, Hobbs HH: Sequence polymorphisms in the apolipoprotein(a) gene. Evidence for dissociation between apolipoprotein(a) size and plasma lipoprotein(a) levels. J Clin Invest 1993;91:16301636.

72 Perombelon YFN, Soutar AK, Knight BL: Variation in lipoprotein(a) concentration associated with different apolipoprotein(a) alleles. J Clin Invest 1994;93:1481-1492.

73 Kim JH, Roh KH, Nam SM, Park HY, Jang Y, Kim DK, Song KS: The apolipoprotein(a) size, pentanucleotide repeat, $\mathrm{C} / \mathrm{T}(+93)$ polymorphisms of apolipoprotein(a) gene, serum lipoprotein(a) concentrations and their relationship in a Korean population. Clin Chim Acta 2001:314:113-123.

74 Kruglyak L, Nickerson DA: Variation is the spice of life. Nat Genet 2001;27:234.

75 Crawford DC, Yi Q, Smith JD, Shephard C, Wong $\mathrm{M}$, Witrak L, Livingston RJ, Rieder MJ, Nickerson DA: Allelic spectrum of the natural variation in CRP. Hum Genet 2006; 119:496-504.

76 Glatt CE, DeYoung JA, Delgado S: Screening a large reference sample to identify very low frequency sequence variants: comparisons between two genes. Nat Genet 2001;27:435.

77 Redon R, Ishikawa S, Fitch KR, Feuk L, Perry $\mathrm{GH}$, Andrews TD, Fiegler H, Shapero MH, Carson AR, Chen W, Cho EK, Dallaire S, Freeman JL, Gonzalez JR, Gratacos M, Huang J, Kalaitzopoulos D, Komura D, MacDonald JR, Marshall CR, Mei R, Montgomery L, Nishimura K, Okamura K, Shen F, Somerville MJ, Tchinda J, Valsesia A, Woodwark C, Yang F, Zhang J, Zerjal T, Zhang J, Armengol L, Conrad DF, Estivill X, TylerSmith C, Carter NP, Aburatani H, Lee C, Jones KW, Scherer SW, Hurles ME: Global variation in copy number in the human genome. Nature 2006;444:444-454. 